\title{
Téoros
}

Revue de recherche en tourisme

\section{Tourisme et environnement}

\section{Normand Cazelais}

Volume 10, numéro 1, mars 1991

Tourisme et environnement

URI : https://id.erudit.org/iderudit/1079810ar

DOI : https://doi.org/10.7202/1079810ar

Aller au sommaire du numéro

Éditeur(s)

Université du Québec à Montréal

ISSN

0712-8657 (imprimé)

1923-2705 (numérique)

Découvrir la revue

Citer ce document

Cazelais, N. (1991). Tourisme et environnement. Téoros, 10(1), 2-2.

https://doi.org/10.7202/1079810ar d'utilisation que vous pouvez consulter en ligne.

https://apropos.erudit.org/fr/usagers/politique-dutilisation/ 
Présentation

\section{Tourisme et environnement}

En soi, l'environnement est un facteur d'attraction touristique. L'objet fondamental du tourisme est de décourvir la planète. De permettre à chacun des humains de constater par lui-même et directement, sur place, à quoi ressemble cette vaste Terre qu'il habite en compagnie d'autres hommes et femmes. De découvrir à quoi ressemble l'ailleurs, un ailleurs façonné -comme l'ici de depart - par des reliefs, des climats, une faune, une flore, des sociétés; bref, partoutce quiconstituel'environnement.

Le touriste sera donc tour à tour à la fois géographe, sociologue, botaniste, amateur d'art et de bonne chère, politicologue. Souvent malgrélui ou de façon inconsciente, il sera curieux, attentif à tous ces stimuli qui le provoquent et l'informent sur l'état physique et culturel de tout ce qui lui est étranger, c'est-à-dire extérieur à son univers quotidien. Par la conscience, les besoins, valeurs et aspirations à son univers qu'il véhicule, par les influences qu'il reçoit et qu'il transmet, le touriste est un agent fort actif d'évolutions environnementale.

Le tourisme fait dorénavant partie du genre de vie des societés jouissant d'un haut niveau de vie. Chaque année, chaque saison, celles-ci expeddient par vagues successives des milliers sinon des millions de personnes vers d'autres horizons, souvent en des régions et pavs économiquement defavorises dont les habitants deviennent à leur tour des partenaires touristiques, le tourisme est d'ailleurs devenu. pour ce, partie prenante de ce qu'il est convenu d'appeler les relations Nord-Sud.

Le tourisme transforme l"environnement. Dans toutes ses dimensions. En raison de son volume, de sa force économique, de sa constance. Cette transformation se fait pour le meilleur et pour le pire. Le plus souvent, avouonsle, pour le pire. II n'est pas une journee en effet sans que les médias nous ramenent a la mémoire des exemples illustrant à quel point le tourisme modifie radicalement les milieux d'accueil: pollution de lacs et de plages, ensembles immobiliers ou hôteliers defigurant des fronts de mer ou des versants de montagnes, spéculation, augmentation de taxes, dépérissement des valeurs des résidents, conflits sociaux, etc. Le tourisme s'avere un agresseur fort dangereux de l'environnement.

Pourtant, a moins d'être absolument masochistes, les sociétés se doivent de concevoir et de promouvoir un tourisme qui sera au contraire un facteur important d'amélioration de l'environnement. Protéger et mettre en valeur l'environnement constituent des moyens pour assurer d'une part la longévité du tourisme - qu'est-ce qu'il yaura à découvrir lorsque tout sera détruit ouavili? -et pour retrouver, d'autre part, l'authenticité et les racines de monde qui nous entoure. L'environnementest une question de respect. Le tourisme devrait l'être également.

Al'aide de consideration théoriques mais aussi d'exemples concrets puisés au Québec et à l'étranger, le présent numero de TÉOROS essaie de circonscrire le cadre et les conditions d'intervention d'un tourisme qui puisse effectivement contribuer de façon significative et durable a la valorisation environnementale de notre planete et de ses constituants, qu'ils soient d'ordre biophysique et humain. Cette approche exige toutefois de développer des attitudes differentes tant chez les voyageurs, les commerçants et les visités qu'au sein des corps publics. Elle demande aussi d"explorer des avenues jusqu'ici négligées, comme en témoigne le cas du tourisme industriel.

Elle demande, bien sûr, de l'imagination, de la créativité et de la concertation. C'est peut-être le meilleur défi qui puisse être lancé au tourisme.

\section{L'UQAM RENFORCE SA COOPERATION AVEC L'OFFICE DES CONGRES ET DU TOURISME DU GRAND MONTRÉAL}

Montréal, le 25 février 1991 - LUniversité du Québec à Montréal et l'Office des Congrès et du Tourisme du Grand Montréal (OCTGM) ont renforcé leur collaboration en signant un accord d'une durée initiale de 3 ans pour assurer aux étudiants une formation tenant compte des besoins des entreprises touristiques et pour réal iser des recherches fondamentales ou appliquées concernant le tourisme.

L'accord, en vigueur dès maintenant, permettra à au moins un étudiant par session inscrit au programme de baccalauréat en gestion et intervention touristiques d'effectuer un stage a l'OCTGM. Les deux organismes collaboreront pour la réalisation et la diffusion de travaux touchant le tourisme et l'OCTGM versera annuellement à l'UQAM la somme de $15000 \$$ pour la réalisation de contrats de recherche. L'université consultera l'OCTGM au sujet de tous les projets de développenent reliés à son programme de baccalauréat en gestion et intervention touristiques et pour la mise sur pied de tout nouveau programmeen tourisme. L'OCTGM allouera également une somme de 10000 \$ annuellement, en 1991 et 1992, au Centre d'études du tourisme en reconnaissance de la contribution de cet organisme à la formation des étudiants et au développement des entreprises touristiques. L'UQAM pourra aussi mettre sur pied des programmes de formation sur mesure pour le perfectionnement et le recyclage des professionnels de l'industrie touristique de la région du Grand Montréal. 